PNL-3618

UC-11

\title{
Measuring Soil Water Content Using Gypsum Blocks with Long Leads
}

R. H. Sauer

P. J. Hof

January 1981

Prepared for the U.S. Department of Energy under Contract DE-AC06-76RLO 1830

Pacific Northwest Laboratory Operated for the U.S. Department of Energy by Battelle Memorial Institute 
This report was prepared as an account of work sponsored by the United States Government. Neither the United States nor the Department of Energy, nor any of their employees, nor any of their contractors, subcontractors, pr their employees, makes any warranty, express or implied, or assumes any legal liability or responsibility for the accuracy. completeness or usefulness of any information, apparatus, product or process disclosed, or represents that its use would not infringe privately owned rights.

The views, opinions and conclusions conrained in this report are those of the contractor and do not necessarilv represent those of the United States Government or the United States Department of Energy.

\author{
PACIFIC NORTHWEST LABORATORY \\ operated by \\ BATTELLE \\ for the \\ UNITED STATES DEPARTMENT OF ENERGY \\ Under Contract DE-AC06-76RLO 1830
}
Printed in the United States of America
tyailabie from
Vational Technical Iniormation Service
Linited States Department of Commerce
5285 Port Roval Road
Springtield, Virginia 22151

Price: Printed Copy 5 $\because$ Microfiche 53.00

\begin{tabular}{c|c}
-Pages & $\begin{array}{c}\text { NTIS } \\
\text { Selling Price }\end{array}$ \\
\hline $001-025$ & 54.00 \\
$026-050$ & $\$ 4.50$ \\
$051-075$ & 55.25 \\
$076-100$ & $\$ 6.00$ \\
$101-125$ & 56.50 \\
$126-150$ & 57.25 \\
$151-175$ & 58.00 \\
$176-200$ & 59.00 \\
$201-225$ & 59.25 \\
$226-250$ & 59.50 \\
$251-275$ & 510.75 \\
$276-300$ & 511.00
\end{tabular}




\section{5}

MEASURING SOIL WATER CONTENT USING

GYPSUM BLOCKS WITH LONG LEADS

R. H. Sauer

P. J. Hof

January 1981

Prepared for the U. S. Department of Energy under contract DE-AC06-76RLO 1830

Pacific Northwest Laboratory

Richland, Washington 99352 



\section{$\underline{\text { ABSTRACT }}$}

This paper describes a system for measuring soil water status quickly and accurately at several sites from a central location. The heart of the system is an instrument, developed at the Pacific Northwest Laboratory, that compensates for the capacitance in the long leads between the gypsum blocks and switching unit that connects each block to the instrument. Advantages of the system are:

- Data collection time can be reduced by as much as 90 percent

- Digital display eliminates interpolation and therefore yields more accurate data

- Damage to the sampling area from trampling or compaction is avoided. 
CONTENTS

\begin{tabular}{|c|c|c|c|c|c|c|c|}
\hline INTRODUCTION & - & • & . & • & $\cdot$ & • & • \\
\hline SYSTEM DESCRIPTION & - & $\cdot$ & - & $\bullet$ & - & - & - \\
\hline DISCUSSIONS AND CON & ICLUSIONS & $\cdot$ & . & 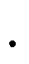 & • & • & $\cdot$ \\
\hline REFERENCES CITED & . & • & - & • & • & • & $\bullet$ \\
\hline
\end{tabular}



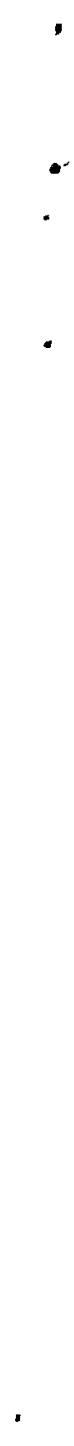


\section{INTRODUCTION}

The need and value for obtaining soil water data in plant studies is well known, but soil water measurement is often difficult. Though many methods exist, none is universally applicable. Several of the more commonly used methods include gravimetric analysis, neutron thermalization, thermocouple psychrometry, and resistance between gypsum-encased electrodes buried in the soil (Black et al. 1965; Hogan et al. 1967; Brown and Johnston 1976; Cannel and Asbell 1964). Choice of any one of these depends upon application. In irrigation studies, for example, data on soil water content are desirable. Gravimetric and neutron thermalization analyses are usually presented as percent water and would be appropriate. Data on soil water potential are preferred in basic research on plant water relations; gypsum blocks and thermocouple psychrometers would be useful here, as results are normally in bars soil water potential. Conversions between percent water and soil water potential are straightforward, requiring a water release curve for the soil in question.

A system to measure soil water potential at four depths for 39 sites was developed as part of a Department of Energy program on restoring vegetative productivity to arid surface mined lands. This system used gypsum blocks because the salt content was not significant and the soil was too rocky to be practical for gravimetric data collection. The gypsum blocks were connected to one of two central switching units by leads of up to $200 \mathrm{~m}$ in length. The switching units allowed the operator to connect any one gypsum block to the resistance measuring instrument. The long leads used to connect the individual gypsum blocks to the central switching units displayed a capacitance with the $A C$ signal used to obtain resistance data from the gypsum blocks. This capacitance masked the resistance of the gypsum block at values above 50,000 ohms when using the commercially available instrument. The instrument and system described in this paper allowed the resistance of gypsum blocks to be measured through long leads in the range of 0 to $10,000,000$ ohms by compensating for the lead capacitance. 
The gypsum biocks were buried at four depths in 39 locations to obtain data on depth and spacial variability in soil water potential. Our experience with these units was that they reliably indicated the differences between wet and ary soil, but were not dependable for showing fine differences in soil water potential. After initial individual calibrations, the blocks were placed into service in 1977 and since have given reliable indications of wet and dry soil conditions.

Leads that varied from 10 to approximately $200 \mathrm{~m}$ in length connected each block individually to the resistance measuring instrument through a set of wafer switches. While connecting one lead from each of the four blocks together by a common lead would have been more economical, a common lead was not used because it was found that the blocks were not electrically isolated in the soil, particularly when the soil was wet. By turning selected switches, each of the 156 blocks was connected to the resistance meter. The resistance meter, described below, gave a reading (in ohms) of the resistance between the screen electrodes in each block. The resistance values were later changed to soil water potential with a computer program that used the gypsum block calibration parameters. 


\section{SYSTEM DESCRIPTION}

The system consists of gypsum blocks (Cannel and Asbell 1964), long leads, a switching unit, the resistance measuring instrument, and data handling programs.

The resistance measuring instrument (Figure 1) was the key to this system. It was field portable, resistant to temperature extremes and jarring, autoranging, had digital readout, measured from 0 to 10,000,000 ohms and, most importantly, compensated for the capacitance of leads (used here) up to $200 \mathrm{~m}$ long. The capacitance was a consequence of using AC current. Alternating current was required for excitation to prevent build-up of charge on the screens in the gypsum block; such a buildup would destroy the gypsum block's ability to provide a meaningful relationship between water potential and resistance between the screens.

The gypsum block and lead assembly functioned as parallel impedances consisting primarily of resistance (the block) and capacitance (the leads). The parallel conductors of the leads functioned as parallel plates of a capacitor; the longer the leads, the greater the capacitance. The greater the lead length and resulting capacitance, the more the lead impedance masked the gypsum block impedance.

The relationship for block resistance and line capacitance in parallel may be given by:

$$
z_{t}=R_{b} x_{c l} /\left(R_{b}^{2}+x_{c l}{ }^{2}\right)^{1 / 2}
$$

where

$$
\begin{aligned}
z_{t} & =\text { total impedance, } \\
x_{c l} & =\text { line capacitance, and } \\
R_{b} & =\text { gypsum block resistance. }
\end{aligned}
$$

At low soil water potentials (dry soil), the high impedance of the gypsum block was masked by the parallel impedance of the leads (if they were long). At high soil water potentials (moist soil) the low impedance of the gypsum block 


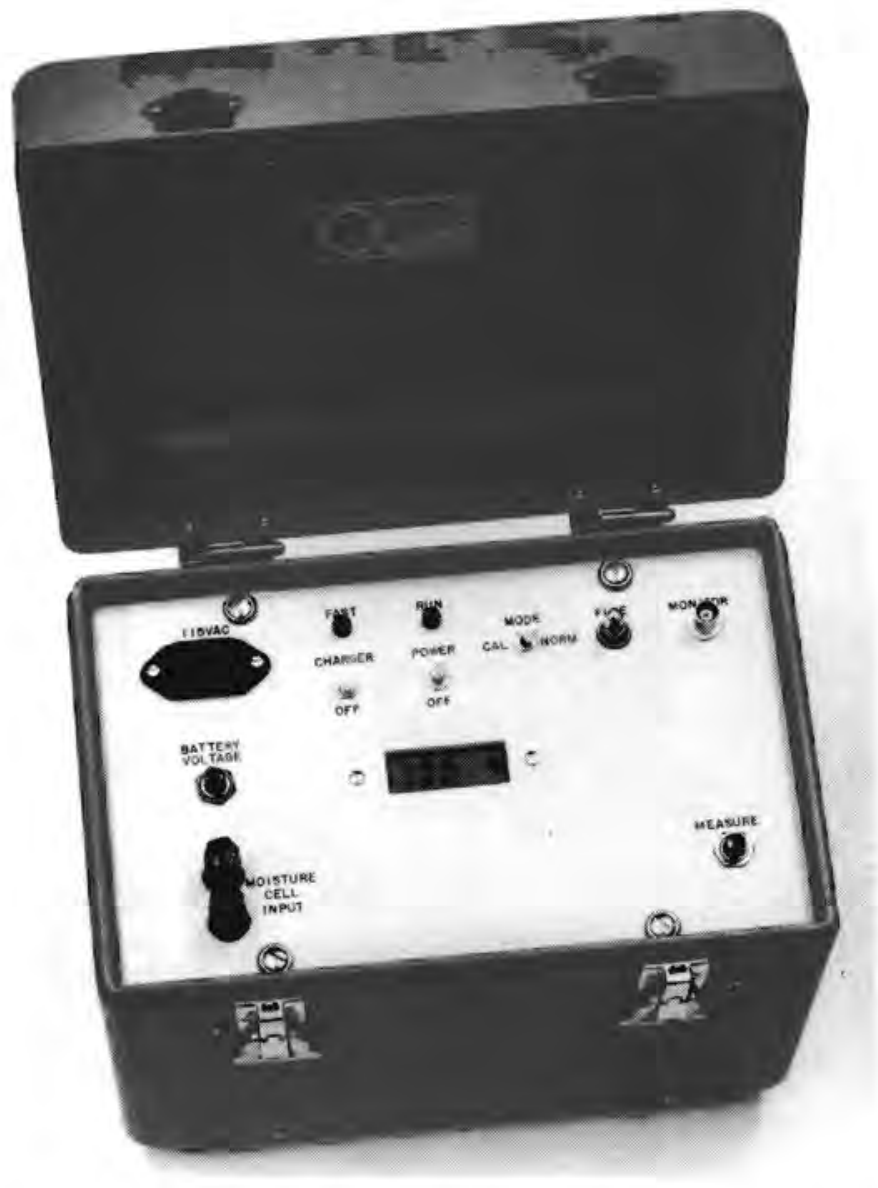

FIGURE 1. Gypsum Block Resistance Measuring Instrument

was relatively unaffected by the considerably higher impedance of the long leads. The measured resistance is greatly affected by the resistance of the gypsum block, excitation amplitude, excitation frequency and series resistance (DC resistance) at low soil water potentials (dry soil). The commercial instrument rectified and averaged the impedance and made no compensation for line capacitance.

The instrument described in this paper dealt with the various measurement problems differently on a range by range basis. All of the logic was contained on four cards:

Cl: Analog signal conditioning for waveform generation and digitizing of the measured analog signal. 
C2: 8085 8-bit microprocessor-based control and data storage unit. Most of the digital components were C-MOS type to reduce power requirements.

C3: Power pack heat sinked charger module for charging the 12 volt battery pack.

C4: Triple DC-DC converter which provided +5 volt logic power and \pm 15 voltage analog power from the 12 volt battery pack. The LCD display and display driver/multiplexer logic were attached to the front panel.

A stable RC 0.625 millisecond clock provided reference for timing in generating the period of the excitation waveforms. Under control of the microprocessor, excitation was generated by a digital-to-analog converter and driver. Output was through series limiting range resistors selected by dip reed relays. On selected ranges, capacitance was applied across the series limiting range resistor. Binary weighted capacitance values were switched in as necessary by di-electrically isolated C-MOS solid-state analog switches. A high impedance voltage follower monitored the measured signal. The output of the high impedance voltage follower was sampled by a high speed (25 $\mu \mathrm{sec}$ ) 10-bit A-D converter for digitizing and storing the measured data. Samples were synchronized with the clock and accrued at a rate of 8 clock ticks per half cycle ( 16 per cycle) during the measurement period. Each time a measurement was requested, a comparator first determined if the battery voltage was low. If so, the measurement cycle was denied and LLL was displayed. Upon receipt of a MEASURE (Figure 1) command, the instrument was activated and selected range one. A $100 \mathrm{~Hz}$ excitation was applied for eight stabilization cycles, followed by a 9 th cycle (read cycle) during which 16 samples were taken, eight per nalf cycle. The absolute values of the 16 samples were averaged. The last value read during each half cycle (see figure 2) was compared with an upper limit (5,000 ohms). If the last value was above this limit, range two was selected. If not, the average data were displayed and the 


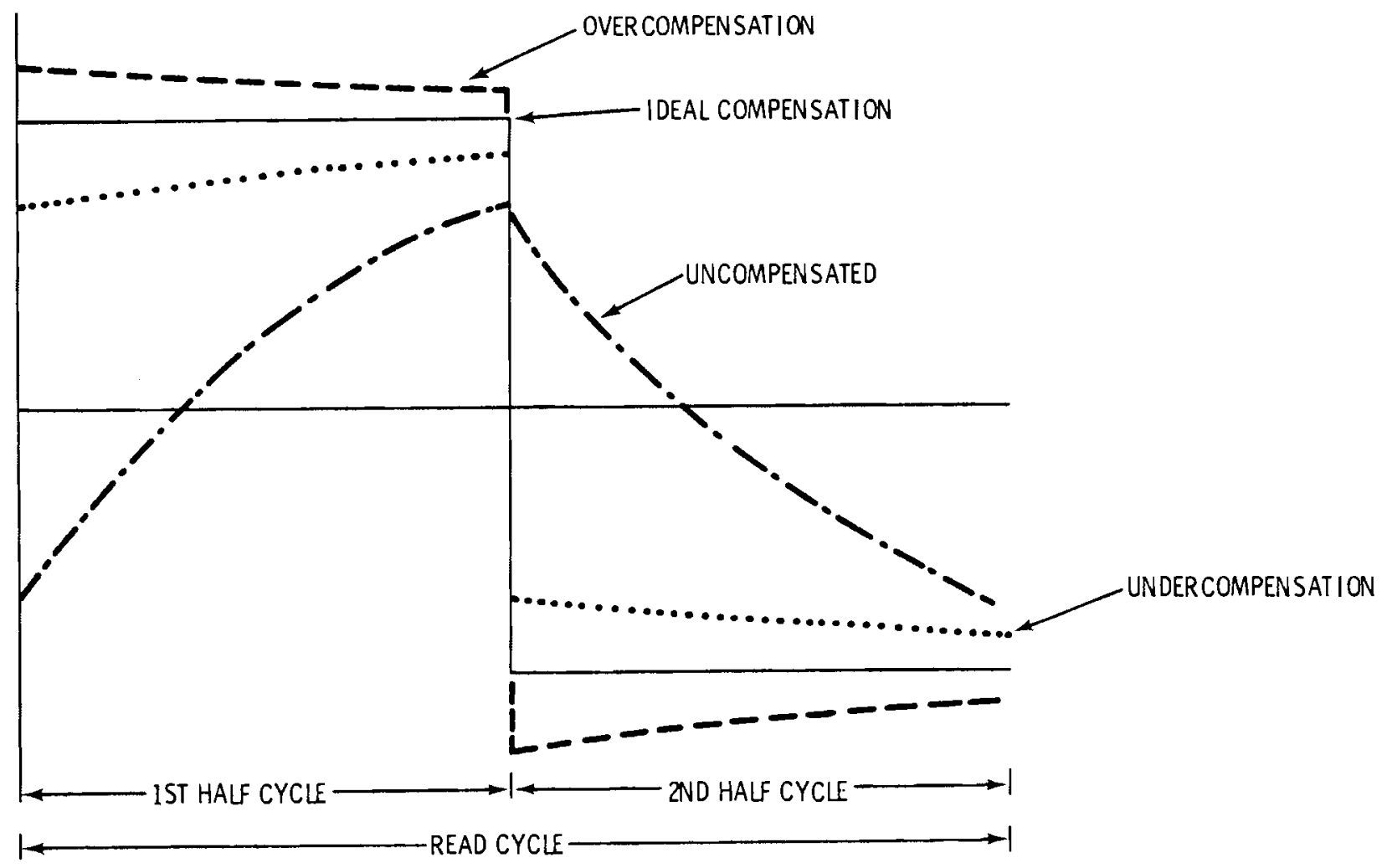

FIGURE 2. Effect of Line Compensation Across the Load as Seen at output Terminals. Compensation is accomplished by a shunting capacitance across the series range register.

microprocessor became inactive to save power. Only the multiplexed display continued to run. The average binary ata from the $A / D$ converter was converted to onms resistance via a look-up table in a separate 2758 type read-only memory.

If the second range was requested, the steps for range one were repeated up through the sampling cycle. If the last value read was greater than 50,000 ohms, range three was selected. If not, only the last four readings of each half cycle were used for averaging and display because line capacitance (if it exists) had a greater impact on the average reading (making it appear too low) than the series capacitance of the gypsum block (now reduced). As series resistance of the gypsum block increased (less moisture), the total impedance became more and more resistive. 
If the third range was requested, the gypsum block under test went through a number of stabilization/measurement cycles. The excitation frequency was reduced from $100 \mathrm{~Hz}$ to $50 \mathrm{~Hz}$. For resistances above 50,000 ohms, the resulting waveform from block excitation should have had the same shape (zero slope) as the output of the squarewave generator (Figure 2). At each measurement cycle an increasing amount of line compensating capacitance was addea across the instrument's series limiting range resistor. When the positive waveform slope was compensated to a point where it became zero or a slightly negative, measurement was complete. The final ( $8 \mathrm{th}$ ) sample of each half cycle was averaged for display. The slope of the waveform was determined by averaging the absolute value of all 16 samples. The average must be greater than or equal to the average of the last set of samples. If at any point along the way to compensating for line capacitance the final reading exceeded 500,000 ohms, the fourth range was selected.

Range four operated in a manner identical to range three. If the final reading in any measurement cycle exceeded $2,000,000$ ohms, the fifth range was selected.

Range five operated in a manner identical to range three. If the final reading in any measurement cycle was equal to or exceeded 10,000,000 ohms, the stabilization/measurement cycles terminated. A message appeared to inform the user that the $A C$ resistance was too high (AAA) or that line capacitance was too great $(C C C)$.

Battery voltage was indicated by pressing the MEASURE and battery voltage buttons simultaneously. Battery voltage was determined by sampling the battery voltage and dividing by 3.5 for the A-D converter. Conversion to engineering units was provided by a table look-up in the same EPROM as for measuring block $A C$ resistance. The microprocessor then became inactive to conserve power. 


\section{DISCUSSION AND CONCLUSIONS}

Information on the amount and distribution of water in the soil is frequently necessary in research on plant productivity or other uses such as monitoring for leaks below storage tanks. It is not always convenient or possible to use short leads on gypsum soil blocks because of the remoteness of the blocks from the resistance measuring instrument. The system, and particularly the instrument described in this paper, can be used to organize and facilitate the collection of soil water data by bringing the leads of the gypsum blocks to a central location where rapid and accurate data can be recorded. This instrument, developed at the Pacific Northwest Laboratory, permits the use of long leads by compensating for the capicitance inherent in long leads when these leads are used with AC current. Advantages of this system include:

- Reduced data collection time. The time required to read 156 sensors was reduced from two hours to 15 minutes.

- Data are more accurate because the digital display eliminates the need to interpolate a meter display visually.

- Damage to the sampling area from trampling or compaction of the observation is avoided.

With the problem of capacitance in long leads solved, it should be possible to consolidate other types of $A C$ resistance measurements for similar increases in efficiency and accuracy. 


\section{ACKNOWLEDGEMENTS}

We sincerely appreciate the effort of Richard Richardson who guided the design of this instrument in its formation stages and the instrument fabrication by Eugene Wallace. This work was funded under DOE's Restoration of

Surface Mined Lands Program, Contract DE-AC06-76RLO 1830. 


\section{REFERENCES CITED}

Black, C. A. (Editor). 1965. Methods of Soil Analysis. Part 1. Physical and Mineralogical Properties, Including Statistics of Measurement and Sampling. Number 9 in the series. American Society of Agronomy. Madison, wisconsin, pp. 98-127.

Brown, R. W., and R. S. Johnston. 1976. Extended field Use of screen-covered thermocouple psychrometers. Agronomy Journal 68(6):995-996.

Cannel, G. H., and C. W. Asbe11. 1964. Prefabrication of mold and construction of cylindrical electrode-type resistance units. Soil Science 17:108-112.

Hogan, R. M., H. R. Haire and T. W. Edminster. 1967. Irrigation of Agricultural Lanas. Number 11 in the series. Agronomy. American Society of Agronomy. Madison, Wisconsin, pp. 275-303. 


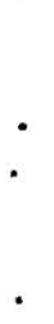


PNL-3618

UC-11

\section{DISTRIBUTION}

No. of

Copies

40 OFFSITE

A. A. Churm

DOE Patent Division

9800 S. Cass Avenue

Argonne, IL 60439

5 Dr. Ralph Franklin

DOE Office of Environmental Health and Research

Ecological Sciences Branch

Washington, D.C. 20545

Or. Helen McCammon

DOE Office of Environmental Health and Research

Ecological Sciences Branch

Washington, D.C. 20545

27 DOE Technical Information Center

Dr. John Thames

School of Renewable Natural Resources

University of Arizona

Tucson, Arizona 85721

$5 \mathrm{Mr}$. Ralph Carter

Argonne National Laboratory 9800 Cass Avenue

Argonne, IL 60439
No. of

Copies

44 ONSITE

2 DOE Richland Operations Office

H. E. Ransom

M. G. White

Rockwell Hanford Operations

J. B. Sisson

41 Pac if ic Northwest Laboratory

D. B. Cearlock

K. E. Harding (5)

N. R. Hinds

P. J. Hoff (10)

T. L. Jones

R. R. Kirkham

P. M. Molton

W. H. Rickard

R. H. Sauer (10)

W. L. Templeton

M. L. Warner

B. E. Vaughan

Publishing Coordination (2)

Technical Information (5) 


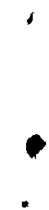

. 